\title{
Role of technology in responding to disasters: insights from the great deluge in Kerala
}

\begin{abstract}
Anamika Ajay
Community action and voluntary initiatives have always played an important role in responding to disasters. However, the sheer scale and pace at which affected communities are now able to mobilize resources and social support reveal the role of communication technology in crisis management. Using the case study of the great deluge in Kerala, this article describes the stages of crowdsourcing that unfolded during the rescue and relief phases, and analyses how technology facilitated this process. The article also demonstrates how simple technologies that are aligned with the local specificities of the context are often more effective in disaster management than technologically advanced equipments.
\end{abstract}

Keywords: Affected communities, crowdsourcing, deluge, disaster management, technology.

THE role of collective action and citizen-led volunteering activities in responding to the great deluge in Kerala is yet another example of how community resilience is a life-saving quality. While local communities have always played an important role in disaster management, the sheer scale and pace at which individuals and groups are being able to come together and support the state-led rescue and relief operations is a rather new phenomenon ${ }^{1}$. Technology has played an important role in facilitating different types of communication between the affected communities and those who offer support and services. The global reach of mobile technology and social media platforms allows people from across the world to participate in the rescue and relief work ${ }^{2}$. There were many instances during the Kerala floods where the non-resident Keralites (NRKs) used social media platforms to reach out to the emergency service providers requesting them to rescue their family members in the state who were directly affected by the disaster ${ }^{3}$. A large proportion of the donations and relief materials received in Kerala during the disaster was sent from various parts of the world. These crowdsourcing activities could not have been possible without effective communication technology in place as well as a citizenry that is both willing and capable of using these technologies. The fact that people in Kerala are one of the largest smartphone users in India ${ }^{4}$, provided a social base for the use of these technologies during disasters. These examples further strengthen the need for more socially consistent technological innovations, especially in the case of disaster management. For this to be achieved, there is need for a broader understanding of

Anamika Ajay is in the National Institute of Advanced Studies, IISc Campus, Bengaluru 560 012, India.

e-mail: anamajay@gmail.com technology. Sen ${ }^{5}$ argues that technology should not be seen as mere inputs or the specific techniques/instruments used in doing something. It also includes the social content which not only influences the choice of a particular technique over the others, but also determines whether there is a social base that is willing and capable of using the techniques.

Although there is wide recognition for the role of communities in responding to crises, policies on disaster management continue to focus on strengthening institutions at the national and sub-national level. To this extent, the objective of this article is to throw light on the crucial role that communities played in the rescue and relief phases of the Kerala deluge of 2018, and evaluate the role of technology in this entire process. This article is based on the experiences of the present author as a digital volunteer during the deluge episode that occurred between 16 and 20 August 2018. A large number of victims as well as their families/friends effectively used the social media and other web-based platforms to exchange information about their situation and also demand specific services like rescue, medical help or relief materials. As part of a large digital volunteering team, the present author collated messages from these various platforms, converted them into a standardized format and shared them with various service providers. The data presented in this article are based on 40 cases of online requests for help coming from 40 localities spread across the worstaffected districts, namely Ernakulam, Thrissur, Pathanamthitta and Alappuzha. Phone calls were made to the individuals who posted these online messages. The first set of calls was made between 16 and 18 August 2018, with the objective of verifying the authenticity of these messages and collect more relevant details that may help the emergency service providers on-ground to 
provide specific support. Based on the data provided by the 40 contact points, approximately 2569 individuals were also stranded in these localities during these three days and were waiting for specific relief and rescue operations. Follow-up calls were made between 1 and 10 September 2018 to these contact points to understand the entire disaster management process in these localities.

\section{Responding to disasters}

Climate change and the concomitant extreme weather events have reached a stage where prevention of many deadly disasters is becoming increasingly difficult. In such cases, the most important task would be to have an effective early warning system that gives enough time to the authorities and communities to get prepared for the disaster $^{6}$. Two issues may affect this process. One is the non-availability of advanced early warning mechanisms which could, in turn, be an outcome of the lack of socioeconomic facilities in a nation that allows for investments in such innovations. The second could be the lack of political or bureaucratic will to apply scientific innovations for the benefit of society ${ }^{7}$. In countries like India, where there is a fairly advanced early warning system for different types of natural and man-made disasters, the issues are most often related to lack of political will. Apart from this, India's science communication strategy is in a nascent stage, which restricts the early warnings issued from getting disseminated to local governments and communities.

The second stage is the spontaneous responses and management of disasters while they occur. Experience from different parts of the world demonstrates that local communities have always been both the most affected as well as the first ones to respond to crisis ${ }^{8}$. Howe ${ }^{9}$ broadly defines crowdsourcing as a method through which a large number of people are mobilized using an open call and are coordinated to perform ad hoc labour. Studies on disaster management have focused on crowdsourcing as a technique used by communities in their responses to disasters, especially when the formal service delivery mechanisms become overwhelmed ${ }^{10}$. It is only through the global reach of social media platforms that virtual volunteering has been made possible ${ }^{11}$. During disasters, volunteers are mobilized, and important tasks are identified and divided among them. These volunteers and service providers may be located in different places or may not have the experience of functioning in such crisis situations. The challenge then is to bring real and virtual volunteers together, assign tasks and coordinate their activities in ways that make disaster management effective ${ }^{12}$. While after every disaster in India, the popular media brings out stories of how citizens used these various platforms to contribute to the crisis management in varied ways, very little is known about how the actual process of crowdsourcing occurs in the country and how various activities of real and virtual volunteers are coordinated. A good starting point to fill this gap would be to draw insights from the comprehensive model proposed by Ludwig et $a l .{ }^{1}$. They provide detailed analysis of the crowdsourcing process to create a public display model which offers all the important information that is required with a single display that would help in assigning tasks, linking the volunteers with affected individuals/families/communities. It identifies categories of actors who play a role in crowdsourcing - (1) local communities who are directly affected by the disaster, (2) volunteers present at the site of the disaster, (3) emergency services and (4) digital volunteers. There is an exchange of information and services between all these actors using technology. The affected communities and local volunteers not only engage in self-help, but also communicate to others and demand for services. The volunteers, both real and virtual, work along with the formal mechanisms to deliver services.

\section{Three stages of responses to the Kerala deluge}

The Kerala deluge revealed many systemic issues in dealing with disasters. Much debate continues to take place on the issues related to early warning systems in Kerala, and whether there were timely responses from the government to these warnings. The failure to respond to the India Meteorological Department warnings given 2-3 days ahead of the actual disaster is raised as a major issue. Despite much advancement in flood modelling systems in India, Kerala and most other flood-prone states in the country had not adopted this technology. A reason often cited by the authorities in Kerala is the fact that there has been no precedence to floods in the last century. Issues have also been raised regarding management of dam water levels, especially when heavy rains are predicted. After the onset of the disaster too, the emergency service providers found it challenging to manage the deluge and landslides because they affected almost all parts of the state, overwhelming the entire government machinery. The second issue is related to the unpredictability of the flow of flooded rivers. The widespread construction and real-estate activities acted as barriers for the rivers to flow through the floodplains, forcing them to move in unpredictable directions. This made it difficult for the local administration to provide evacuation services. These factors implied that the communities were left with no choice but to respond to the disaster while it occurred.

\section{Responses by the affected communities}

The most immediate response to the disaster came from the affected communities themselves. As the rains continued incessantly from 8 August, the dam water levels 
GENERAL ARTICLES

Table 1. Responses of the affected communities to the disaster

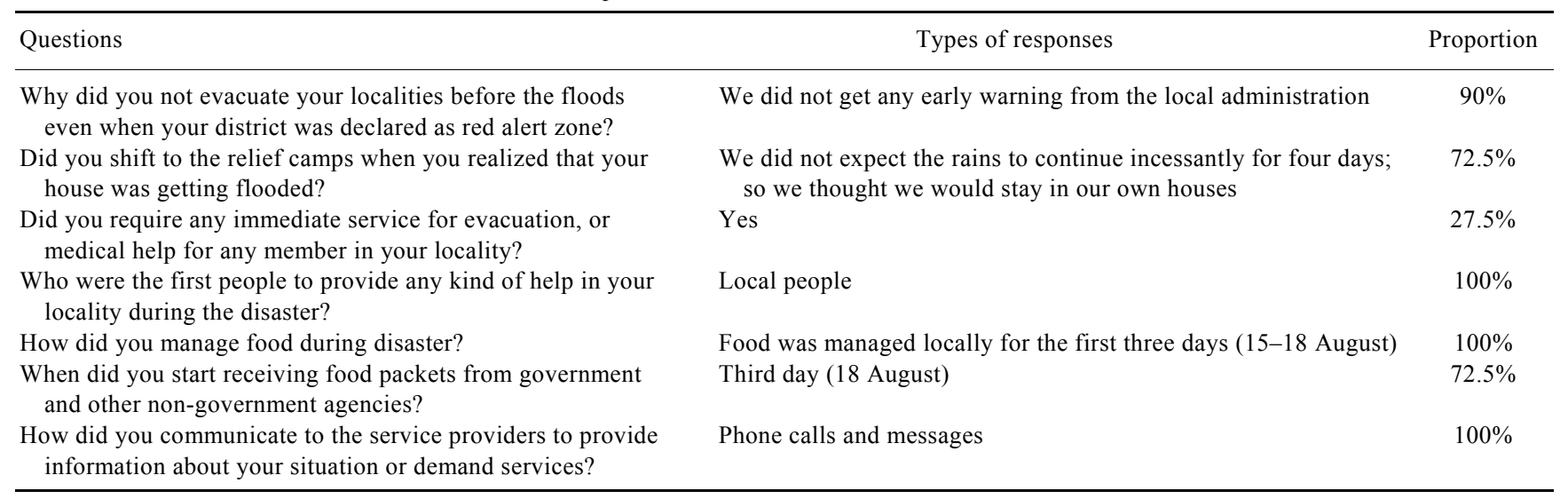

Source: Primary data collected through telephonic interviews, 2018.

also rose beyond capacity which forced the authorities to open the shutters of many dams. In areas like Idukki, both the administration and dam management authorities gave information to most local areas that were likely to get flooded if the dam shutters were to be opened. Consequently, the district and local administration were able to evacuate many vulnerable families to safer areas. However, the decisions on many other dams in the state were taken urgently due to the incessant rains and therefore, the information did not reach the local communities on time. All the 40 respondents spread across Ernakulam, Pathanamthitta, Thrissur and Alappuzha districts suggested that the first responses to the disaster came from the affected communities themselves (see Table 1). In 36 out of 40 localities, no early warning was received by the local communities. As a result, people could respond only after their immediate surroundings started flooding. In one case, the respondent said that people were staying awake at night to see if their houses were getting flooded and information was shared with others in the locality through phone calls. Local communities handled activities right from exchanging key information to coordinating first responses. Table 1 provides a summary of the responses of the affected communities on some aspects related to disaster management.

The affected communities provided the base for all the disaster management activities that occurred later through the service providers by providing situated information. For instance, in all the localities for which data were collected, phone calls were made to panchayat officials to find out about the status of the rescue operations. Phone calls were also made to families/friends who were living in less-affected parts of Kerala or outside to pass on information regarding their situation, exact location, number of people stranded in the localities, relief materials required and demand for medical support, if necessary. This effective use of communication technology was only possible because of the specific social context. Kerala is the largest consumer of smartphones and has had many state-led initiatives on improving digital literacy its people. Both these factors enabled the people of Kerala across rural and urban areas to use their phones and social media as an effective disaster management tool.

As an immediate response to the crisis, the informants suggested that families begin congregating on the terraces of bigger houses, schools, religious institutions and hospitals in their localities to prevent isolation of any family. Shifting of essential materials and people, especially senior citizens, children, pregnant women to these taller buildings was facilitated by the local people. In $27.5 \%$ of the localities, demands for urgent evacuation or medical help were raised from certain families in the locality. In all these cases, local individuals who had larger vehicles like jeeps, trucks and lorries helped evacuate people and material on the first day itself. Families who stayed back in the waterlogged localities mostly shifted to higher floors of buildings, whenever possible.

Many reported that from 15 to 18 August 2018 families managed food locally. Women initiated common kitchens in which food materials from houses were collected and prepared from a single kitchen and served. A middle-aged woman suggested that she was making food for her neighbours, but since it was impossible to carry the prepared food by road due to floods she had made a balconyto-balcony ropeway through which she sent them food. The shortage of food in individual houses was compensated through community sharing and new sharing techniques were innovated depending on the situation. In many cases, the local shop owners, including supermarkets and ration shops distributed food and other essential materials free of cost to the affected victims.

All these proactive initiatives of the local communities during the disaster were coordinated using two key communication channels - face-to-face interactions and mobile technology. However, by the second and third day of the floods when the mobile phones collapsed due to 
power failure in Kerala, the ability of the local communities to respond to the disaster deteriorated considerably. Nonetheless, there were many other actors who were sourced in to respond to the needs of the affected communities.

\section{Responses to the affected communities}

Role of state-led rescue and relief operations: As the ability of the affected communities to respond to the disaster reduced after the first couple of days of incessant rains and flooding due to fatigue and resource constraints, the primary role of rescue and relief was conducted by state and non-state service providers. Among these, the government disaster management teams, state government machineries and the local governments played an important role. The disaster management operation undertaken in Kerala was the largest one of the National Disaster Response Force (UDRF) in India. Around 58 NDRF specialized teams were deployed along with Army, Navy, Air force, Paramilitary forces and Coast Guard to provide rescue and relief services to the areas affected. These formal service providers were able to evacuate more than 10,000 people, rescue hundreds of lives and deliver relief materials to thousands of people ${ }^{13}$. They received key information from the local administration and the State Disaster Management teams. However, in many cases, the NDRF teams that reached the affected sites did not possess local knowledge, as a result of which they were dependent on the local administration, local volunteers and the victims themselves for their operations. For instance, in many localities in Ernakulam and Pathanamthitta districts, it was reported that the emergency service providers were overwhelmed by the demand for services. Realizing that the formal emergency services would not be adequate to provide such large-scale support, the state government made an open call for participation to the citizens.

Role of non-local family members and friends: The NRKs played a critical role in coordinating the activities between affected victims and various kinds of services, especially after the collapse of mobile-phone network in many parts of Kerala by 17 August 2018. When no direct contact was possible with the affected victims, the NRKs took to social media platforms to circulate information regarding their affected family members/friends. They posted information on various online platforms regarding the exact location at which their family members were stranded. This helped the formal emergency rescue teams to locate affected victims and arrange for timely service. The NRKs also used the information of service providers which were made available on various online platforms to reach out to them directly and share details of their relatives or friends who required rescue or relief support in Kerala.
Role on non-state actors like individual volunteers and civil society: Due to incessant rains, river flooding and landslides across Kerala, the government machinery for rescue and relief services was overwhelmed. In such a scenario, there was high dependence on volunteers and civil society organizations to fulfil various on-ground ad hoc tasks. Among the volunteers from different walks of life, members of the fisher communities were involved in the most critical activity which was to evacuate or rescue families that were stranded in the floods. As noted above, Navy boats and helicopters could not be operated due to lack of elbow space for operations in areas with dense populations. More importantly, the large elderly population in Kerala was unable to physically access these big boats or helicopters due to their health conditions. Hence, the country boats brought by the fishermen from across the Kerala coast were able to rescue more people than the motorized large boats brought in by the NDRF teams. From the localities for which data were collected, $80 \%$ of them reported that the final rescue and evacuation was done in country boats which carried them to nearby roads from where they were transferred to the Navy boats which ferried them to relief camps or points. In cases where the fishermen did not possess knowledge about the roads and location, they required local volunteers to assist them. Similar services were offered by doctors, nurses, government officials, media persons and college students, who were crowdsourced and allocated with responsibilities on the ground. Many nongovernmental organizations, charity institutions and religious institutions supported the affected communities by providing space to set up relief camps and donating essential relief materials.

Role of the digital volunteers and social media: One of the unique features of the crowdsourcing process that unfolded during the management of the Kerala deluge was the active participation of digital volunteers, who effectively used social media and other web-based applications. When the local mobile networks failed, the formal institutions and other service providers used these online platforms to coordinate rescue and relief activities. Their primary responsibility was to collate all these online messages posted by the victims and the service providers into a platform that could be easily accessed by the government, which could then transfer the information to local rescue and relief teams. However, since these messages were located in varied and incompatible platforms, these online messages were not verified and also did not follow a standardized format. In order to standardize their format and verify their authenticity, virtual volunteers were called upon. They not only collated and standardized these messages into a single format, but also made calls to verify and collect information that is necessary for the on-ground teams to provide timely and specific services. The digital volunteers contributing to Kerala rescue and 


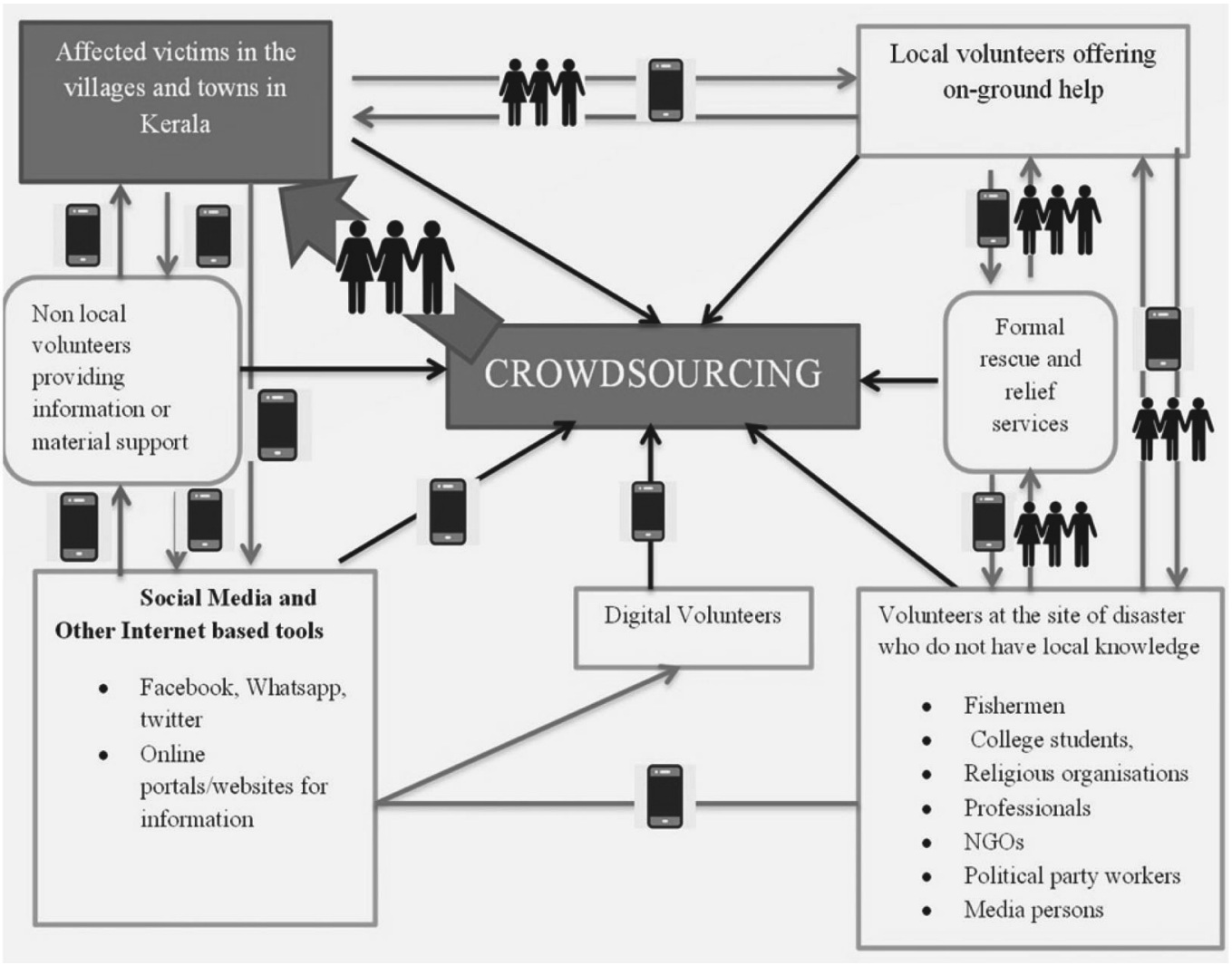

Figure 1. Role of technology in crowdsourcing during disasters - a basic model. Source: Author's analysis.

relief work were most active between 16 and 25 August 2018. These digital volunteers worked closely with the volunteers working on-ground to make sure that the information available on online platforms was updated. Tapping into their services, the Kerala government initiated a web-based application (www.keralarescue.in) to provide an online platform for information management and coordination among victims, volunteers and service providers. Thousands of entries on the victims, nature of relief and rescue services required and also information regarding online volunteers, relief camps in various districts, and contact information of the disaster management teams were made available on this platform during the disaster. Many non-state IT agencies also developed similar mobile and web-based applications, where situated information was collected from the victims, volunteers and service providers.

\section{Role of technology in crowdsourcing during disasters}

Using the case study of the Kerala deluge, three stages have been identified in responding to the disaster - early warning, responses by the affected communities, and responses to the affected communities by various service providers. Figure 1 illustrates a basic model which pro- vides the key steps involved in crowdsourcing that occurred after the onset of the disaster, the key actors involved and the modes of communication between these actors.

As illustrated, the first responses to the disaster came from the affected communities. Apart from initiating selfhelp activities and providing first-level rescue and relief operations, they also reached out to two other actors at this stage. The first is the local-level administration like the Panchayats and local volunteers to demand help and also enquire about the status of the rescue operations. These communications occurred through face-to-face interactions but when physical mobility became difficult, mobile phones were preferred. During this stage, the affected communities also reached out to their non-local friends and families, and updated them with situated information and also sought help, whenever possible, using mobile phones and social media platforms. In many cases, the affected communities sent their location details, information on the number of people trapped due to the floods and also whether any emergency services were required. The next stage is the responses of the various stakeholders to the affected communities. The NRKs used mobile phones and social media to demand rescue and relief services on behalf of their family members directly affected by the floods. This became especially relevant when the local mobile network in Kerala collapsed 
completely. The service providers also responded to these demands using online platforms to show their readiness to help and also shared key information about their operations. Since these interactions between the service providers and those who were requesting help occurred in an unstructured manner and on multiple online platforms, a need arose for digital volunteers who collated the information on a single platform, verified these messages and also coordinated the crowdsourcing activities, wherever possible, using mobile phones, web-based applications and social media platforms.

\section{Implications}

The Kerala experience offers some key lessons for disaster management in India. First, it makes a case for the need to urgently adopt all technologies to predict disasters and provide early warning to the vulnerable communities. Secondly, it makes a strong case for the decentralization of disaster management and creation of local disaster management teams at Panchayat/urban ward-level by tapping into the already existing networks like self-help groups, National Cadet Corps, clubs in schools and colleges, local elected representatives, and so on. Thirdly, in this era of mobile phones and social media, Kerala's case shows how these technologies can be used as effective tools in rescue and relief operations. Thus, it may not be imprudent if we think of power banks as one of the essential relief materials like food, water and medicines that should be distributed during disasters. Most importantly, every measure should be taken to build resilient communities that are capable of coping with disasters.

1. Ludwig, T., Kotthaus, C., Reuter, C., van Dongen, S. and Pipek, V., Situated crowdsourcing during disasters: Managing the task of spontaneous volunteers through public displays. Int. J. Hum.Comput. Stud., 2016, 102, 103-121.

2. Reuter, C., Heger, O. and Pipek, V., Combining real and virtual volunteers through social media. In Proceedings of the Information Systems for Crisis Response and Management (ISCRAM), Baden-Baden, Germany, 2013, pp. 1-10.

3. Mandhani, N., How Indians are using social media to help floodhit Kerala. BBC News, 20 August 2018; https://www.bbc.com/ news/world-asia-india-45218556 (last accessed on 30 August 2018).
4. Paul, A. and Pillai, R., On the road to digitization: the case of Kerala, IIMK Case Study, IIMK/CS/41/ITS/2017/06, Indian Institute of Management, Kozhikode; https://www.iimk.ac.in/ websiteadmin/FacultyPublications/Cases/41abs.pdf (last accessed on 1 October 2018).

5. Sen, A. K., Gender and cooperative conflicts. Working Paper 18, World Institute for Development Economics Research, Helsinki, 1987.

6. Zschau, J. and Kuppers, A. N. (eds), Early Warning Systems for Natural Disaster Reduction, Springer Science and Business Media, New York, USA, 2013.

7. Mener, A., Disaster response in the United States of America: an analysis of the bureaucratic and political history of a failing system, CUREJ: Coll. Undergrad. Res. Electron. J., http:// repository.upenn.edu/curej/63 (last accessed on 3 October 2018).

8. Stallings, R. and Quarantelli, E., Emergent citizen groups and emergency management. Public Adm. Rev. (Special Issue), 1985, 45, 93-100.

9. Howe, J., The rise of crowdsourcing, Wired Mag., 2006, 14(6), 14; https://sistemas-humano-computacionais.wdfiles.com/local--files/ capitulo $\% 3$ Aredes-sociais/Howe The Rise of Crowdsourcing.pdf (last accessed on 3 October 2018).

10. Gao, H. and Barbier, G., Harnessing the crowdsourcing power of social media for disaster relief. IEEE Intell. Syst., 2011, 26(3), 10 14.

11. Starbird, K. and Palen, L., 'Voluntweeters': self-organizing by digital volunteers in times of crisis. In Proceedings of the SIGCHI Annual Conference on Human Factors in Computing Systems, CHI, 2011, p. 1071; http://cmci.colorado.edu/ palen/voluntweetersStarbirdPalen.pdf (last accessed on 3 October 2018).

12. Palen, L., Anderson, K. M., Mark, G., Martin, J., Sicker, D., Palmer, M. and Grunwald, D., A vision for technology-mediated support for public participation and assistance in mass emergencies and disasters. In Proceedings, ACMBCS Visions of Computer Science Conference, Edinburgh, United Kingdom, 2010, pp. 1-12.

13. Press Trust of India, NDRF launches biggest ever operations in flood-hit Kerala; 58 teams deputed. Economic Times, 18 August 2018; https://economictimes.indiatimes.com/news/politics-andnation/ndrf-launches-biggest-ever-operation-in-flood-hit-kerala58-teams-deputed/articleshow/65452069.cms (last accessed on 3 October 2018).

ACKNOWLEDGEMENTS. I thank Prof. Narendar Pani and Prof. V. S. Ramamurthy (National Institute of Advanced Studies, Bengaluru) for their support and valuable comments. I also thank all participants of the 'Round Table Discussion on the Flood in Kerala and Kodagu Region: Lessons' organized by National Institute of Advanced Studies, Bengaluru, during which an earlier version of this paper was presented, and Manipal Academy of Higher Education for institutional support during my doctoral studies.

Received 11 October 2018; accepted 16 January 2019

doi: $10.18520 / \mathrm{cs} / \mathrm{v} 116 / \mathrm{i} 6 / 913-918$ 